\title{
A STUDY ON PHYTOCHEMICALS, ANTIMICROBIAL, AND SYNERGISTIC ANTIMICROBIAL ACTIVITIES OF HIBISCUS SABDARIFFA
}

\author{
SIVAN KUMAR, ANNA SHEBA L* \\ Department of Biochemistry, Vels Institute of Science, Technology and Advanced Studies, Chennai, Tamil Nadu, India. \\ Email: lawrencesheeba@gmail.com
}

Received: 17 March 2018, Revised and Accepted: 08 March 2019

\section{ABSTRACT}

Objective: The aim of the present study was to screen phytochemical constituents and evaluate antimicrobial and synergistic antimicrobial properties of leaves and stem of Hibiscus sabdariffa.

Methods: The extraction was done by cold maceration method using 80\% aqueous methanol. The antimicrobial efficacy and synergistic antimicrobial activity were carried out by disc diffusion assay against the bacteria Staphylococcus aureus and Pseudomonas aeruginosa.

Results: Phytochemical analysis revealed the presence of carbohydrate, protein, alkaloids, phytosterols, flavonoids, and diterpenes in both the leaves and stem extracts while saponins, phenol, and tannins were found to be present only in the leaf extract. Both the extracts inhibited the tested bacteria with minimum inhibitory concentration value of $10 \mathrm{mg} / \mathrm{ml}$. Aqueous methanolic extract of leaf showed higher antibacterial activity against $S$. aureus and $P$. aeruginosa and also exhibited synergistic activity with the antibiotic chloramphenicol against $S$. aureus.

Conclusion: The present study concludes that $H$. sabdariffa is a potential source of bioactive components and also provides information on synergistic activity of leaf extract. The results can contribute to the development of potent antibacterial agents.

Keywords: Hibiscus sabdariffa, Synergistic effect, Antimicrobial, Phytochemicals.

(C) 2019 The Authors. Published by Innovare Academic Sciences Pvt Ltd. This is an open access article under the CC BY license (http://creativecommons. org/licenses/by/4. 0/) DOI: http://dx.doi.org/10.22159/ajpcr.2019.v12i4.31597

\section{INTRODUCTION}

From time immemorial traditional culture in the world is associated with medicinal plants. These medicinal plants are exploited as a source of ingredients in traditional medicine. They contain vast array of phytoconstituents for combating chronic and infectious diseases and ailments. These phytoconstituents are probably secondary metabolites playing an integral role for the survival of plants including growth regulation, inter- and intra-specific interactions, and protection against predators and infection $[1,2]$.

Infection and infectious agents exist from the beginning of life. Infectious diseases are still the world's leading cause of mortality. However, the mortality rate caused by pathogens has been decreasing slowly. While considering the statistics related to number of deaths annually from $1990-2010$, it has been found out that there is a decline of only $1 \%$ per year. Reports of the World Health Organization have suggested that there will be 13 million deaths associated to these causes in 2050 [3].

For many decades, plants have been traditionally used as the source of antimicrobial substances. Ethnobotanical studies have revealed the importance of plants in treating infectious diseases. Some of the major antimicrobial compounds produced by plants include phenolics, polyphenols, terpenoids, essential oils, lectins, polypeptides, and alkaloids. Plant extracts containing these compounds provide an enhanced effect [4]. These compounds act on bacteria through different mechanisms: "Inactivation of proteins, adhesins, and enzymes, block cell-to-cell signaling pathways and quench production of virulence factors (e.g., exotoxins) [5,6], and disrupt or inhibit the formation of biofilms" [7-9].

Hibiscus sabdariffa L. (Family: Malvaceae), also known as Roselle or Sorrel, is native to Asia (India to Malaysia) or tropical Africa. The plant is widely distributed in India, Caribbean, Africa, Central America,
Brazil, Hawaii, Florida, Australia, and the Philippines. In Indian languages, it is known as Gongura, Lalambari, Patwa (Hindi), Lal-mista, Chukar (Bengali), Lal-ambadi (Marathi), Pulicha Keerai (Tamil), Yerra gogu (Telugu), Pulachakiri, Pundibija (Kannada), Polechi, Pulichchai (Malayalam), and Chukkiar (Assam) [11]

It is a dicotyledonous, annual or perennial herb or woody-based subshrub, growing 2-2.5 m tall. Different parts of this plant comprise vast and diverse phytochemicals. $H$. sabdariffa is enriched with quercetin, luteolin, chlorogenic acid, protocatechuic acid, pelargonic acid, sitosterol and ergosterol, hydroxycitric acid, delphinidin-3sambubioside, and cyaniding-3-sambubioside [12]. In folk medicine, it is widely utilized as a remedy for various ailments such as cough, fever, hangover, debility, dyspepsia, bilious conditions abscess, heart diseases, hypertension, and neurosis $[13,14]$. The plant is reported to exhibit antioxidant, nephro- and hepato-protective, renal/diuretic effect, anticholesterol, antidiabetic, antihypertensive, antihyperuricemic and antiarthritic effects [15-17]. It modulates obesity through its antioxidant mechanism, and fat metabolism, namely reduction in adipogenesis, fat absorption, and excretion [18]. It is used to resist various intestinal infections added that $H$. sabdariffa flowers can be used in relaxing the pain of muscles of the uterus and intestine. Furthermore, it exhibits extensive antibacterial properties. Its purplish sepals (calyx and epicalyx) rich in anthocyanin are used economically in food (Jam and Jelly) and cosmetic industries as a source of natural coloring agent [19].

Despite the development made in understanding the microbes and progress of control measures, incidents of epidemics pose a serious public health issue. This is due to the advent of drug-resistant microorganisms and unknown microbial diseases. Resistance to drugs can be natural or acquired. Mutation changes or genetic combination are considered to be the cause of the resistance of microorganism to the antimicrobial drugs [10]. Thus, the unreceptiveness of microorganisms to the modern medicines and the safety and side effect issues drives 
for the renewed interest for alternate medicine. Synergism finds a breakthrough attention to fight against microorganism, particularly resistant microorganisms. Further, in the current scenario, synergism among plant extracts and antibiotic is of renewed interest. Hence, in the present study, leaves and calyces of $H$. sabdariffa are screened for their phytochemical constituents and their antibacterial and synergistic antibacterial activities are evaluated.

\section{MATERIALS AND METHODS}

\section{Collection of plant material}

Plant was collected near the areas of Pallavaram, Chennai, India. The collected plant material was then authenticated by Dr. P. Jayaraman, Plant Anatomy Research Centre, Chennai, Tamil Nadu. The plant materials (leaf and stem) were then thoroughly washed with tap water and dried under shade. The dried plant parts were homogenized to a fine powder and used for extraction.

\section{Preparation of plant extract}

About $10 \mathrm{~g}$ of each of the powered samples were extracted with $80 \%$ aqueous methanol for 5 days. After filtration using cheesecloth, the filtrate was refiltered again using Whatman No.1 filter paper to remove fine residues in the filtrate. Methanol and water were evaporated while extracts were then obtained.

\section{Qualitative phytochemical analysis}

Phytochemical analysis of $H$. sabdariffa was done with the leaf and stem extracts by following the standard procedures [20]. All the crude extracts were analyzed for the presence of alkaloids, carbohydrates, saponins, protein, phenols, diterpenes, steroids, flavonoids, glycosides, and tannins.

\section{Microbial samples}

The test organisms include Gram-positive Staphylococcus aureus ATCC29213 and Gram-negative Pseudomonas aeruginosa ATCC15442. The bacteria were cultured in the nutrient broth $37^{\circ} \mathrm{C}$ and maintained on nutrient agar slants at $4^{\circ} \mathrm{C}$.

\section{In vitro antibacterial activity}

In vitro antibacterial activity was examined for aqueous methanolic extract of leaves and stem of $H$. sabdariffa. Antimicrobial activities of these extracts were evaluated by disc diffusion method [21]. For all the bacterial strains, overnight cultures grown in broth were adjusted to an inoculum size of $2 \times 10^{6}$ colony-forming units (CFU) $/ \mathrm{ml}$ with $0.5 \mathrm{McFarland}$ standard and inoculated in the agar plates [22]. Petri plates were prepared with $15 \mathrm{ml}$ of sterile Mueller-Hinton agar. The test culture $\left(0.1 \%\right.$ of a suspension containing $10^{6} \mathrm{CFU} / \mathrm{ml}$ bacteria) was swabbed and allowed to dry for $10 \mathrm{~min}$. Sterile $6 \mathrm{~mm}$ discs were impregnated each with appropriate extract of different concentrations $20 \mathrm{mg} / \mathrm{ml}, 40 \mathrm{mg} / \mathrm{ml}, 80 \mathrm{mg} / \mathrm{ml}$, and $160 \mathrm{mg} / \mathrm{ml}$. The loaded discs were placed on the surface of medium and the extract was allowed to diffuse for $5 \mathrm{~min}$ and the plates were kept for incubation at $37^{\circ} \mathrm{C}$ for $24 \mathrm{~h}$. Reference antibiotic chloramphenicol of concentration $10 \mathrm{mg} / \mathrm{ml}$ was used.

\section{Minimum inhibitory concentration (MIC)}

MIC is "the least concentration of an antimicrobial that will hinder the visible growth of a microorganism after overnight incubation [23]." For determining MIC, a modified dilution method was performed [24]. Each extract was diluted into various concentrations of $10,8,6,4$, and $2 \mathrm{mg} / \mathrm{ml}$ in sterile nutrient broth in test tubes. Using standard wire loop, a loopful $(10 \mu \mathrm{l})$ of P. aeruginosa, $0.5 \mathrm{McF}$ arland standard, was inoculated into test tubes containing $1 \mathrm{ml}$ of the various concentrations of the appropriate extracts in nutrient broth. Similarly, this was repeated for S. aureus. Incubation of the tubes was carried out at $37^{\circ} \mathrm{C}$ for 18-24 h, and thereafter, growth or turbidity was observed.

\section{Evaluation of the synergistic effect}

Synergistic antimicrobial activity was done using disc diffusion method with modifications. Agar plates were inoculated with the tested microorganisms. Extract showing maximum antibacterial activity was taken for the study of synergistic activity. Sterile $6 \mathrm{~mm}$ discs were impregnated with appropriate extract of the concentration of 20-160 mg and antibiotic of the concentration of $10 \mathrm{mg} / \mathrm{ml}$ and allowed to saturate for $30 \mathrm{~min}$ and are placed on the agar plates. All the plates were then subjected to incubation at $37^{\circ} \mathrm{C}$ for $24 \mathrm{~h}$. Zone of inhibition (ZOI) that appeared around the discs was measured and recorded.

$$
\text { Synergistic effect } \%=(B-A) / A \times 100
$$

Where, A is ZOI for the antibiotic and B is ZOI for the antibiotic+the plant extract $[25,26]$.

\section{Statistical analysis}

The experimental results were expressed as mean \pm standard error of triplicates.

\section{RESULTS AND DISCUSSION}

The present work attempt to establish in vitro synergy between aqueous methanolic extract of the medicinal plant and commonly used antibiotic (chloramphenicol) emphasizing the potential role of phytochemicals in increasing the effectiveness of antibiotics.

\section{Preliminary phytochemical analysis}

The leaves and stem aqueous methanolic extracts of $H$. sabdariffa were subjected to preliminary phytochemical analysis. The analysis indicated the presence of carbohydrate, protein, alkaloids, phytosterols, flavonoids, and diterpenes in both the leaves and stem extracts, whereas saponins, phenol, and tannins were found to be present only in the leaf extract. Alkaloids, saponins, tannins, flavonoids, phenols, and several other aromatics have the capability to resist microbial invasion [27]. It is documented that the chemical structure of the phytochemicals plays an important role in determining antibacterial activity. For instance, flavonoids which are hydroxylated phenolic substance are synthesized by plants in response to microbial infection. They complex with extracellular and soluble proteins and also with bacterial cell wall [4]. Saponins exhibit antibacterial activity by causing leakage of bacterial protein and enzymes [28]. Its biological activity depends on its aglycone part or number of sugar residues [36]. Similarly, basic character of tannins enables it to bind with proteins and damage bacterial cell membrane. Tannins also hinder microbial growth by precipitating microbial protein and make nutritional proteins unavailable [29]. Thus, H. sabdariffa has been found to be the reservoir of phytochemicals and capable of exhibiting antibacterial activity against number of diseases. The overall result is tabulated in Table 1.

\section{Evaluation of antibacterial activity}

$S$. aureus and $P$. aeruginosa were tested to evaluate the antibacterial activity of $H$. sabdariffa. Different parts of $H$. sabdariffa showed variable antibacterial potential and they responded to the tested bacteria in a varied manner (Fig. 1). The leaf and stem extracts of H. sabdariffa

Table 1: Phytochemical analysis of $H$. sabdariffa leaves and stem extracts

\begin{tabular}{llll}
\hline \multirow{2}{*}{ S. No. } & Phytochemical & \multicolumn{2}{c}{ H. sabdariffa } \\
\cline { 3 - 4 } & & Leaf & Stem \\
\hline 1 & Alkaloids & + & + \\
2 & Carbohydrates & + & + \\
3 & Saponins & + & - \\
4 & Phytosterols & + & + \\
5 & Phenols & + & - \\
6 & Tannins & + & - \\
7 & Flavonoids & + & + \\
8 & Proteins and amino acids & + & + \\
9 & Diterpenes & + & + \\
10 & Glycosides & - & - \\
\hline$+:$ Presence, & $-:$ Absence, H. sabdariffa: Hibiscus sabdariffa &
\end{tabular}


inhibited the tested bacteria with MIC value of $10 \mathrm{mg} / \mathrm{ml}$. The result of this investigation revealed that at different concentration (20-160 mg/ml) leaves of $H$. sabdariffa were effective showing higher inhibitory actions against $S$. aureus and $P$. aeruginosa than the stem extract (Table 2). The bacteria responded to stem extract only at higher concentration (80 and $160 \mathrm{mg} / \mathrm{ml}$ ) (Table 3). Meanwhile, leaves of

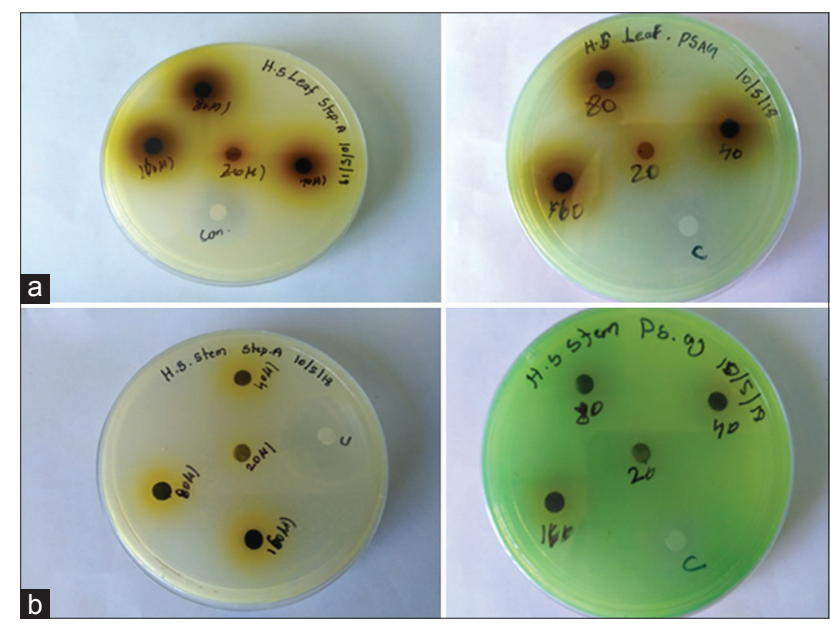

Fig. 1: Antibacterial activity of the aqueous methanolic extract of Hibiscus sabdariffa, (a) leaf, (b) stem

Sa: Staphylococcus aureus, Pa: Pseudomonas aeruginosa

Table 2: Antibacterial activity of leaves and stem extracts of Hibiscus sabdariffa

\begin{tabular}{lll}
\hline Conc. $\mathbf{~ m g} / \mathbf{m l}$ & \multicolumn{2}{l}{ Inhibition zone $(\mathbf{m m})$} \\
\cline { 2 - 3 } & S. aureus & P. aeruginosa \\
\hline 20 & $5 \pm 0.4$ & $6 \pm 0.08$ \\
40 & $8 \pm 0.23$ & $11 \pm 0.56$ \\
80 & $10 \pm 0.45$ & $11 \pm 1.00$ \\
160 & $11 \pm 1.58$ & $12.33 \pm 0.56$ \\
Control $(10 \mathrm{mg} / \mathrm{ml})$ & $20 \pm 0.00$ & $10 \pm 0.47$ \\
\hline
\end{tabular}

Values are expressed as Mean \pm SE, Control: Chloramphenicol, S. aureus:

Staphylococcus aureus, P. aeruginosa: Pseudomonas aeruginosa

Table 3: Antibacterial activity of aqueous methanolic extract of the stem of Hibiscus sabdariffa

\begin{tabular}{lll}
\hline Conc. $\mathbf{~ m g} / \mathbf{m l}$ & \multicolumn{2}{l}{ Inhibition zone $(\mathbf{m m})$} \\
\cline { 2 - 3 } & S. aureus & P. aeruginosa \\
\hline 20 & - & - \\
40 & - & - \\
80 & $5 \pm 0.18$ & - \\
160 & $9 \pm 0.12$ & $6 \pm 0.14$ \\
Control $(10 \mathrm{mg} / \mathrm{ml})$ & $26 \pm 0.14$ & $11 \pm 0.12$ \\
\hline
\end{tabular}

Values are expressed as Mean \pm SE, Control: Chloramphenicol, P. aeruginosa:

Pseudomonas aeruginosa, S. aureus: Staphylococcus aureus
H. sabdariffa demonstrated antibacterial activity in a dose-dependent manner. This observation is in agreement with a study in which leaves of $H$. sabdariffa were found to inhibit Gram-positive bacteria: Bacillus cereus, Micrococcus luteus, and S. aureus and Gram-negative bacteria: Escherichia coli, P. aeruginosa, and Salmonella choleraesuis [31]. In another study, aqueous extract of root and calyx of $H$. sabdariffa demonstrated marked antibacterial activity than that of stem [32]. The potent antibacterial properties of the leaves of $H$. sabdariffa could be attributed to its richness in phytochemicals. Studies are successful in isolating proteins from plant extracts and demonstrating its efficiency as antimicrobial agent [30]. Our phytochemical studies revealed the presence of alkaloids, phenolic compounds, flavonoids, and saponins. These compounds are considered to be the major groups of antimicrobial compounds in plants.

\section{Synergistic antibacterial activity}

Synergistic/additive interactions occur as a result of a combined effect of active compounds from extracts and antibiotics. Phytochemicals play an important role in dealing synergism as they have an impact on growth and metabolism of microorganisms [4].

The aqueous methanolic extract of the leaves of $H$. sabdariffa which reported to have higher antibacterial activity has been chosen for synergistic study and the results are shown in Table 4.

Synergistic activity of H. sabdariffa leaves and antibiotic chloramphenicol was carried out to find the effectiveness against $S$. aureus and $P$. aeruginosa. It was evident that the above-said combination exhibited an identical effect with $P$. aeruginosa but synergistic effect with $S$. aureus at higher concentration $(160 \mathrm{mg} / \mathrm{ml})$. Such synergistic effect was observed with aqueous extract of $H$. sabdariffa calyces and the antibiotic clarithromycin, amoxicillin, or metronidazole against Helicobacter pylori strains [33]. However, in one another study, $H$. sabdariffa calyces exhibit synergistic effect against fungal strains but not with bacteria [34]. Several studies have reported synergistic activity at higher concentration. For example, when lemon balm was studied with ampicillin for synergism at a concentration range of $5-400 \mathrm{mg} / \mathrm{ml}$, it was found that it is susceptible to Klebsiella pneumonia at $200 \mathrm{mg} / \mathrm{ml} \mathrm{[35].} \mathrm{Such} \mathrm{a} \mathrm{combination} \mathrm{therapy} \mathrm{can} \mathrm{be} \mathrm{effective} \mathrm{as} \mathrm{it}$ increases the efficacy of antibiotic by either blocking or circumventing resistance mechanisms.

\section{CONCLUSION}

Nowadays, renewed interest has been developed to explore alternate treatment to reduce the dose of antibiotics, particularly combination of plant extract and synthetic antibacterial agents. Apparently, low or non-toxicity of plant preparations and their low cost as compared to synthetic drugs envisage its use as antibacterial agents. Based on the results, it is concluded that antibacterial activity of aqueous methanolic extract of the leaves of $H$. sabdariffa is found to be effective against both the tested bacteria and exhibits synergism along with antibiotic, chloramphenicol against $S$. aureus. Thus, the combination of natural antibacterial agent and antibiotic will pave a way for alternative treatment for infections. In future, more insight has to be carried out to confirm these activities as well as the mechanisms of action in vivo.

Table 4: Synergistic antibacterial activity of aqueous methanolic extract of the leaves of Hibiscus sabdariffa

\begin{tabular}{|c|c|c|c|c|c|}
\hline \multicolumn{6}{|l|}{ Zone of inhibition } \\
\hline \multirow[t]{2}{*}{ Microorganism and synergism } & \multicolumn{4}{|c|}{ Extract+antibiotic $(\mathrm{mg} / \mathrm{ml})$} & \multirow{2}{*}{$\begin{array}{l}\text { Chloramphenicol }(\mathrm{mg} / \mathrm{ml}) \\
10\end{array}$} \\
\hline & 20 & 40 & 80 & 160 & \\
\hline S. aureus & $16 \pm 0.2$ & $20 \pm 0.4$ & $20 \pm 0.4$ & $23 \pm 0.4$ & $20 \pm 0.3$ \\
\hline Combination effects & A & I & I & S (64\%) & \\
\hline P. aeruginosa & - & - & - & $10 \pm 0.2$ & $10 \pm 0.4$ \\
\hline Combination effects & - & - & - & I & \\
\hline
\end{tabular}

Values are expressed as Mean \pm SE, Antibiotic: Chloramphenicol, S: Synergism, I: Identical, S. aureus: Staphylococcus aureus, P. aeruginosa: Pseudomonas aeruginosa 


\section{AUTHORS' CONTRIBUTIONS}

All authors have equal contribution in bringing out this article.

\section{CONFLICTS OF INTEREST}

None.

\section{REFERENCES}

1. Verpoorte R. Exploration of nature's chemodiversity: The role of secondary metabolites as leads in drug development. Drug Discov Today 1998;3:232-8.

2. Verpoorte R. Pharmacognosy in the new millennium: Lead finding and biotechnology. J Pharm Pharmacol 2000;52:253-62.

3. O'Neill J. Review on Antimicrobial Resistance Antimicrobial Resistance: Tackling a Crisis for the Health and Wealth of Nations. London: Review on Antimicrobial Resistance; 2014.

4. Dye C. After 2015: Infectious diseases in a new era of health and development. Philos Trans R Soc Lond B Biol Sci 2014;369:20130426.

5. Cowan MM. Plant products as antimicrobial agents. Clin Microbiol Rev 1999;12:564-82.

6. Cech NB, Junio HA, Ackermann LW, Kavanaugh JS, Horswill AR. Quorum quenching and antimicrobial activity of Goldenseal (Hydrastis canadensis) against Methicillin-resistant Staphylococcus aureus (MRSA). Planta Med 2012;78:1556-61.

7. Quave CL, Lyles JT, Kavanaugh JS, Nelson K, Parlet CP, Crosby HA, et al. Castanea sativa (European Chestnut) leaf extracts rich in ursene and oleanene derivatives block Staphylococcus aureus virulence and pathogenesis without detectable resistance. PLoS One 2015; 10:e0136486.

8. QuaveCL,Estévez-Carmona M,CompadreCM,Hobby G,HendricksonH, Beenken KE, et al. Ellagic acid derivatives from Rubus ulmifolius inhibit Staphylococcus aureus biofilm formation and improve response to antibiotics. PLoS One 2012;7:e28737.

9. Sarkar R, Chaudhary SK, Sharma A, Yadav KK, Nema NK, Sekhoacha M, et al. Anti-biofilm activity of Marula - A study with the standardized bark extract. J Ethnopharmacol 2014;154:170-5.

10. Talekar SJ, Chochua S, Nelson K, Klugman KP, Quave CL, VidalJE.220D-F2 from Rubusulmifolius kills Streptococcus pneumoniae planktonic cells and pneumococcal biofilms. PLoS One 2014; 9:e97314.

11. Coculescu BI. Antimicrobial resistance induced by genetic changes. J Med Life 2009;2:114-23.

12. Mahadevan N, Shivali A, Kamboj P. Hibiscus sabdariffa Linn.- An overview. Nat Prod Rad 2009;8:77-83.

13. Piyatida P, Kato-Noguchi H. Evaluation of allelopathic activity of H. sabdariffa L. Adv Biol Res 2011;5:366-72

14. Sastri BN. Hibiscus sabdariffa Linn. The Wealth of India, A Dictionary of Indian Raw Materials and Industrial Products. New Delhi: Council of Scientific and Industrial Research; 1959. p. 446.

15. Nadkari KM. Hibiscus sabdariffa Linn. Indian Materia Medica. $3^{\text {rd }}$ ed. Mumbai: Bombay Popular Prakashan; 1976. p. 632

16. Fahmi Z. Potential healing effects of Hibiscus sabdariffa L. flowers on arthritis. Int J Pharm Pharm Sci 2014;7:300-3.

17. Wahyuningsih S, Sukandar S, Sukransoand Lofika D. Antihyperuricemia activity of the ethanol extract of Roselle calyx and its fraction (Hibiscus sabdariffa Linn) on male wistar rat. Int J Pharm Pharm Sci 2016;8:
278-80.

18. Da-Costa-Rocha I, Bernd B, Hartwig S, Ivo P, Michael H. Hibiscus sabdariffa L. - A phytochemical and pharmacological review. Food Chem 2014;165:424-43

19. Sheba LA, Ilakkia A. Anti-obesity effect of Hibiscus sabdariffa L. - A review. Int J Pharm Bio Sci 2016;7:341-5.

20. Ubani CS, Joshuva PE, Anieke UC. Effects of aqueous extract of Hibiscus sabdariffa L. calyces on liver marker enzymes of phenobarbitoneinduced adult wistar albino rats. J Chem Pharm Res 2011; 3:528-37.

21. Harborne JB. Phytochemical Methods: A Guide to Modern Techniques of Plant Analysis. ${ }^{\text {st }}$ ed. London: Chapman and Hall Ltd.; 1973. p. 49-188.

22. Rios JL, Recio MC, Vilar A. Screening methods for natural products with antimicrobial activity: A review of the literature. J Ethnopharmacol 1988; 23:127-49

23. Collins CH, Lynes PM, Grange JM. Microbiological Methods. $7^{\text {th }}$ ed. Britain: Butterworth Heinemann Ltd.; 1995. p. 175-90.

24. Chikezie IO. Determination of minimum inhibitory concentration (MIC) andminimum bactericidal concentration (MBC) using a novel dilution tube method. Afr J Microbiol Res 2017;11:977-80.

25. Rakholiya K, Chanda S. In vitro interaction of certain antimicrobial agent in combination with plant extracts against some pathogenic bacterial strains. Asian Pac J Trop Biomed 2012;2:876-80.

26. Gurunathan S, Han JW, Kwon DN, Kim JH. Enhanced antibacterial and anti-biofilm activities of silver nanoparticles against gram-negative and gram-positive bacteria. Nanoscale Res Lett 2014;9:373

27. Bonjar GH, Nik AK, Aghighi S. Antibacterial and antifungal survey in plants used in indigenous herbal-medicine of South East regions of Iran. J Biol Sci 2004;4:405-12.

28. Zablotowicz RM, Hoagland RE, Wagner SC. Effect of saponins on the growth and activity of rhizosphere bacteria. Adv Exp Med Biol 1996; 405:83-95

29. Abirami S, Nishanthini K, Poonkothai M. Antimicrobial activity and phytochemical screening of the leaf extracts of Eucalyptus globulus. Int J Curr Pharm Res 2017;9:85-9.

30. Manisha T, Anjali B, Ajeet S. Isolation of antibacterial protein/peptide from Ficus glomerata leaf. Int J Curr Pharm Res 2016;8:24-7.

31. Edwards-Jones V. Alternative antimicrobial approaches to fighting multidrug-resistant infections. In: Rai M, Kon K, editors. Fighting Multidrug Resistance with Herbal Extracts, Essential Oils and their Components. Amsterdam: Elsevier Inc.; 2013. p. 1-9.

32. Wong SK, Lim YY, Chan EW. Evaluation of antioxidant, anti-tyrosinase and antibacterial activities of selected Hibiscus species. Ethnobot Leaflets 2010;14:781-96.

33. Ajagbonna OP, Oshagbemi HO, Olorede BR. Antibacterial properties of calyx, stem bark and root of Hibiscus sabdariffa. Niger J Nat Prod Med 2001;5:54-5.

34. Hassan ST, Berchová K, Majerová M, Pokorná M, Švajdlenka E. In vitro synergistic effect of Hibiscus sabdariffa aqueous extract in combination with standard antibiotics against Helicobacter pylori clinical isolates. Pharm Biol 2016;54:1736-40.

35. Abdelraouf AE, Amany AA, Nedaa AA. Antibacterial, antifungal and synergistic effect of Lawsonia inermis, Punica granatum and Hibiscus sabdariffa. Ann Alquds Med 2011;7:33-41.

36. Nascimento GG, Locatelli J, Freitas PC, Silva GL. Antibacterial activity of plant extracts and phytochemicals on antibiotic-resistant bacteria. Braz J Microbiol 2000;31:247-56. 